\title{
Knowledge towards Chronic Kidney Disease Manifestations in Saudi Arabia
}

\author{
Fahad A. Alateeq ${ }^{1}$, Abdulmalik M. Aloriney', Saleh Hadi Alharbi', Ibrahim A. Bin Ahmed', \\ Abdullah Abdulhadi Hammad Alharbi², Abdul Rahman Ali AlSogair², \\ Ali Dawood Mohmmed Almansour ${ }^{2}$, Alanoud Mansour Ayed Albalawi2 \\ Hussain Gadelkarim Ahmed ${ }^{2}$
}

${ }^{1}$ Faculty of Medicine, Al Imam Mohammad Ibn Saud Islamic University, Riyadh, KSA

${ }^{2}$ College of Medicine, University of Hail, Hail, KSA

Email: hussaingad5@gmail.com

How to cite this paper: Alateeq, F.A., Aloriney, A.M., Alharbi, S.H., Bin Ahmed, I.A., Alharbi, A.A.H., AlSogair, A.R.A., Almansour, A.D.M., Albalawi, A.M.A. and Ahmed, H.G. (2018) Knowledge towards Chronic Kidney Disease Manifestations in Saudi Arabia. Open Journal of Preventive Medicine, 8, 315-323.

https://doi.org/10.4236/ojpm.2018.811027

Received: October 11, 2018

Accepted: November 10, 2018

Published: November 13, 2018

Copyright $\odot 2018$ by authors and Scientific Research Publishing Inc. This work is licensed under the Creative Commons Attribution International License (CC BY 4.0).

http://creativecommons.org/licenses/by/4.0/

\section{(c) (i) Open Access}

\begin{abstract}
Background: Increasing awareness level and health education can reduce the burden of Chronic Kidney Disease (CKD) at community base. Therefore, the aim of the present study was to assess the level of knowledge towards CKD manifestations in Saudi Arabia. Methodology: This is a descriptive prospective study including 900 apparently health Saudi volunteers, their ages ranging from 18 to 65 years old with a mean age of 34 years. A purposeful questionnaire was deliberated and used for obtaining data about the CKD. Results: Out of 900 contributors, 268 (29.8\%) were males and $632(70.2 \%)$ were females, giving males:females ratio of 1.00:2.36. About 102/900 (11.3\%) of the participants (all of them were females) were found to believe that CKD has no specific symptoms. Conclusion: The awareness towards CKD manifestation is relatively low, which necessitates the important of community based intervention including health educational programs.
\end{abstract}

\section{Keywords}

CKD, Saudi Arabia, Awareness, Manifestations

\section{Introduction}

Chronic kidney disease (CKD) is emerging as a major public health problem worldwide [1]. The global prevalence of CKD is estimated to be $8 \%-16 \%$ [2]. $\mathrm{CKD}$ is associated with diverse serious medical conditions, such as, cardiovascular disease (CVD), mineral and bone disease, adverse metabolic and nutritional consequences, infections, reduced cognitive function, cognitive decline, anemia 
and increased risk of acute kidney injury [1] [2]. Death from CVD is 8- to 10 -fold higher in CKD patients compared to non-CKD individuals. The global epidemiology of CKD reveals an increasing incidence and prevalence of CKD, which might be attributed to the global increasing prevalence rates of diabetes mellitus (DM), hypertension (HTN), and obesity [1]. CKD remains asymptomatic till late stage when intervention fails to stop the progression of the disease. Screening and intervention can prevent the progression CKD to end-stage kidney disease (ESKD) [3] [4]. This necessitates the need of a global effort to raise awareness of $\mathrm{CKD}$, to incorporate prevention of CKD progression program in the public health agenda and to implement programs for early screening and detection of CKD, especially in high-risk population [1]. In order to reduce the consequences of $\mathrm{CKD}$ at both, individual and societal levels, promoting primary prevention (elimination of risk factors), secondary prevention (early management of patients) or tertiary prevention (optimal treatment of functional disabilities related to CKD) seems relevant [5].

$\mathrm{CKD}$ is defined as a reduced glomerular filtration rate, increased urinary albumin excretion, or both [2]. The most widely used definition of CKD is by the National Kidney Foundation's Kidney Disease Outcome Quality Initiative stating Glomerular Filtration Rate (GFR) $<60 \mathrm{ml} / \mathrm{min} / 1.73 \mathrm{~m}^{2}$ that is present for 3 months or more; or evidence of kidney damage for 3 months or more with or without decreased GFR as evidenced by any of the following: Microalbuminuria, Macro-albuminuria, Proteinuria, Glomerular Hematuria, Pathological abnormalities, Anatomical abnormalities [6].

In recent years, Saudi Arabia has witnessed a rapid increase in the prevalence of CKD. This tremendous increase is attributed to the rapid changes in lifestyle, high population growth, fast increase in life expectancy, and massive urbanization. This is in addition to the major CKD influencing factors such as, very high rate of diabetic nephropathy, hypertension, obesity and shift in age demographics [7] [8] [9] [10]. Therefore, the aim of the present study was to assess the level of knowledge towards CKD manifestations in Saudi Arabia.

\section{Materials and Methods}

In this prospective descriptive study, data were obtained from 900 Saudi volunteers during the period from January to August 2018. Participants were randomly selected by simple random regardless of their age, gender or education level. People were met in different public places including university, clubs, etc. No specific inclusion or exclusion criteria was adopted. Sample size was calculated using Survey Software applying 95\% confidence interval, available at: https://www.surveysystem.com/sscalc.htm.

Purposeful questionnaire was designed and used for collection of the required data. The following information were obtained from each participant: age, sex, occupation, education level, Prior knowledge about CKD, Have you CKD, The nature of $\mathrm{CKD}$ is, the type of $\mathrm{CKD}$ is, Human can live with one kidney, CKD can 
easily treated if early detected, CK needs transplantation.

\subsection{Data Analysis}

Statistical Package for Social Sciences (SPSS) was used for analysis and to perform Pearson Chi-square test for statistical significance (P value). The $95 \%$ confidence level and confidence intervals were used. $P$ value less than 0.05 was considered statistically significant.

\subsection{Ethical Consent}

Each participant was asked to sign a written ethical consent during data collection. The informed ethical consent form was designed and approved by the ethical committee of the College of Medicine (University of Hail, KSA) Research Board.

\section{Results}

This study surveyed 900 Saudi volunteers living in Northern Saudi Arabia, their ages ranging from 18 to 65 years old with a mean age of 35 years. Out of 900 contributors, $268(29.8 \%)$ were males and $632(70.2 \%)$ were females, giving males' females' ratio 1.00:2.36.

The distribution of the participants by demographical characteristics was described in Table 1, Figure 1, the majority of the participants were found at age range 19 - 25 years constituting 348 (55\%) followed by age groups 45 - 55, and $\geq 56$ years constituting 179 (20\%), and 145 (16\%), respectively. The majority of males were found at age group 45 - 55 years followed by age groups 19 - 25 years, representing $86(32 \%), 65$ (21\%), of the total males, in this order. The majority of females were found at age group 19 - 25 years followed by age groups $\geq$ 56 years, representing $292(46.2 \%), 119(18.8 \%)$, of the total Females, in this order.

Most of the study subjects were found with university level of education followed by secondary level, constituting 426 (47.3\%), 422 (47\%), correspondingly. For males, most of them were found at secondary level constituting 138/268 (51.5\%) out of the total males' number, hence, most females were found with university level comprising 318/632 (50\%) of the total females, as described in Table 1, Figure 1.

With regard to the occupation, most participants were students followed by teachers representing $363(40 \%)$, and $228(25.3 \%)$ respectively. For males, most of them were military representing 72/268 (27\%), hence, most of females were students comprising 328/632 (52\%), as described in Table 1 .

Table 2 summarizes, the distribution of the participants by clinical manifestation according to participants' point of view. About 102/900 (11.3\%) of the participants (all of them were females) believed that CKD has no specific symptoms. All of males were found to consider that CKD has specific symptoms (100\%). A round 293/900 (32.6\%) of the contributors thought that HTN is a sign of CKD. 
Table 1. Distribution of the participants by demographical characteristics.

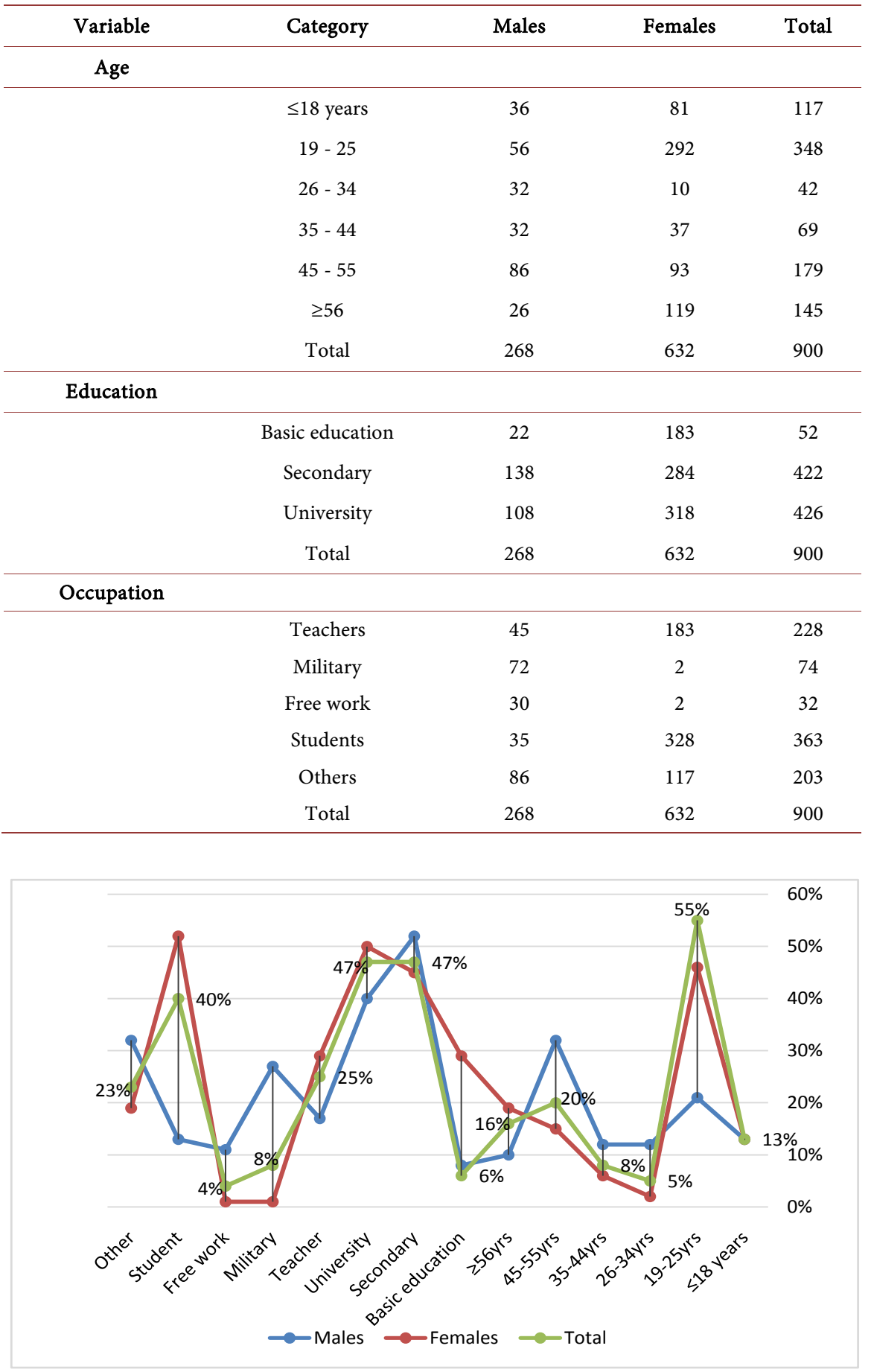

Figure 1. Description of the study subjects by demographical characteristics.

Out of the 293 participants, 140/268 (52.2\%) were males and 153/632 (24.2\%) were females. Approximately, 130 (14.4\%), 138 (15.3\%), 617 (68.6\%), 662 (73.6\%), $752(83.6 \%)$, and $672(74.7 \%)$ of the participants supposed that, thirst, polyuria, anuria, urine smell change, side pain, and difficulty in urination are symptoms of CKD respectively, as shown in Figure 2. 
Table 2. Distribution of the participants by clinical manifestation according to participants' point of view.

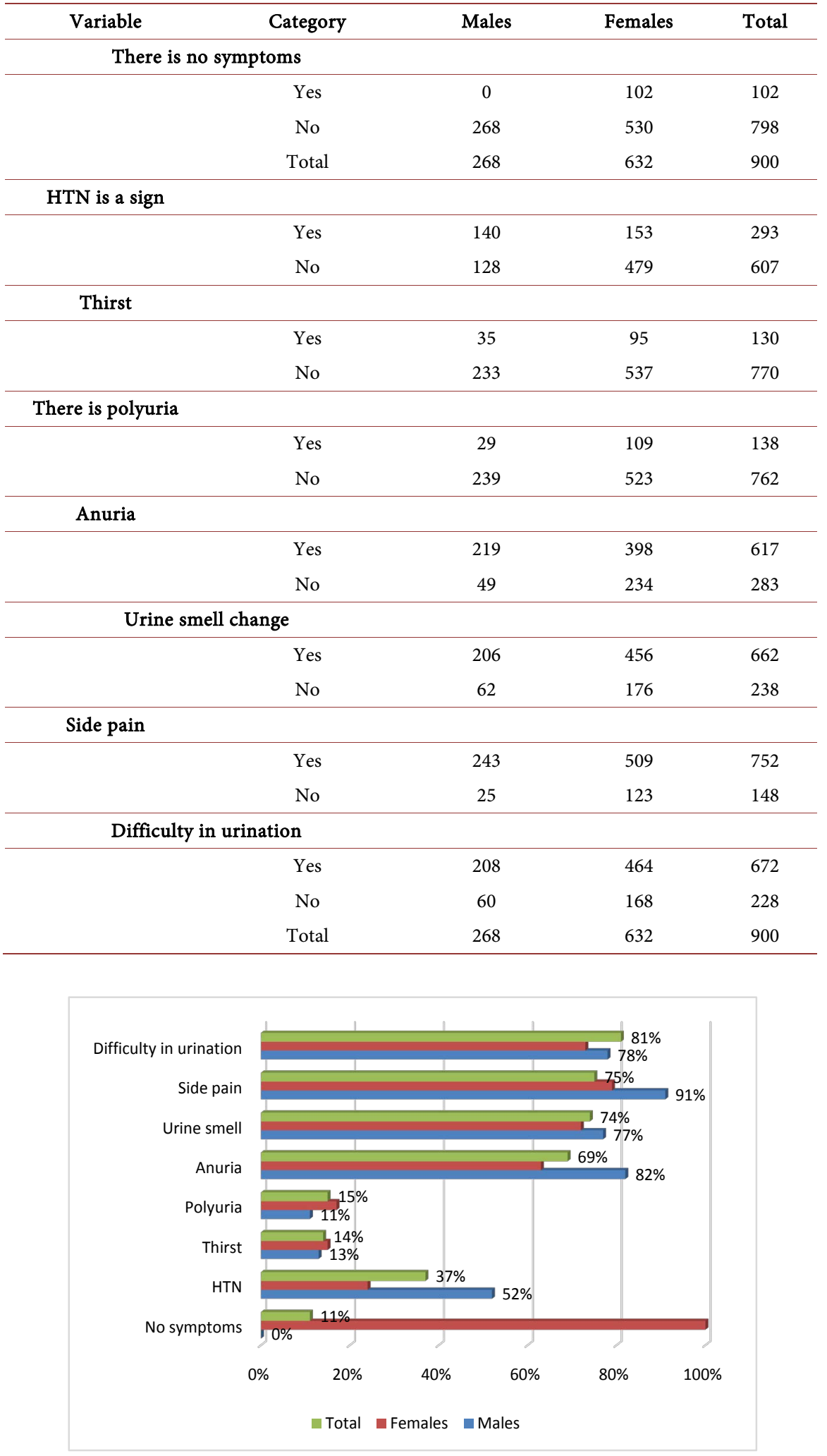

Figure 2. Description of the participants by their perceptions in each gender group. 
With regard to the CKD status, about 149/900 (16.7\%) participants experienced a previous renal test for detection of CKD, of whom 105/268 (39.2\%) were males and $44 / 632(7 \%)$ were females. As a result of renal test, only 16/900 (1.8\%) of the participants were found with CKD, of whom 12/268 (4.4\%) were males and 4/632 (0.6\%) were females. Consequently the CKD is more common among Saudi males compared to females and this was found to be statistically significant $\mathrm{P}<0.05$. Out of 16 patients with CKD, 11/16 (68.8\%) were detected through doctor visit, $2 / 16$ (12.5\%) through symptoms and 3/16 (18.7\%) during comprehensive laboratory investigations, as indicated in Table 3.

\section{Discussion}

$\mathrm{CKD}$ is a raising public health problem in Saudi Arabia, due to the tremendous increasing in its risk factors in recent years. Because of the rapid change in lifestyle in Saudi Arabia, there is a wonderful elevation in the prevalence rates of DM, HTN and obesity, which are the leading causes of CKD. Therefore, there is an urgent need for implementing effective preventive measures including raising of the awareness through planned health educational programs. Consequently and as an awareness effort, this study was aiming at assessing the level of Knowledge towards CKD manifestations in Saudi Arabia.

This study comprised diverse population section with variable age groups, education levels and occupation, as specified in the results. However, there is outnumber of females compared to males, thus, the variables were manipulated in each gender group. The females' predominance in this study was due to high response of women compared to men.

Table 3. Distribution of the participants by CKD status.

\begin{tabular}{|c|c|c|c|c|}
\hline Variable & Category & Males & Females & Total \\
\hline \multicolumn{5}{|c|}{ Did a renal test } \\
\hline & Yes & 105 & 44 & 149 \\
\hline & No & 163 & 588 & 751 \\
\hline & Total & 268 & 632 & 900 \\
\hline \multicolumn{5}{|c|}{ Renal test results } \\
\hline & No CKD & 93 & 40 & 133 \\
\hline & Yes CKD & 12 & 4 & 16 \\
\hline & Total & 105 & 44 & 149 \\
\hline \multicolumn{5}{|c|}{ Mean of detection } \\
\hline & Doctor visit & 7 & 4 & 11 \\
\hline & Symptoms & 2 & 0 & 2 \\
\hline & $\begin{array}{l}\text { Comprehensive } \\
\text { investigations }\end{array}$ & 3 & 0 & 3 \\
\hline Total & & 12 & 4 & 16 \\
\hline
\end{tabular}


About $11.3 \%$ of the participants (all of them were females) were found to suppose that CKD has no specific symptoms. All of males were found to suppose that CKD has no specific symptoms (100\%). It was well known that the early stages of CKD may not reveal specific symptoms, but some symptoms may appear by progression to more severe stages of the disease [11]. A round $32.6 \%$ of the contributors thought that HTN is a sign of CKD. About $52.2 \%$ were males and $24.2 \%$ were females. HTN and CKD are meticulously interconnected with an intermingled cause and effect association. Blood pressure (BP) typically rises with declines in kidney function, and continued rises in $\mathrm{BP}$ accelerate progression of CKD. HTN in patients with CKD is often go together with a decline in the kidney's ability to remove salt [12].

About $14.4 \%$ of the participants think that thirst is one of the symptoms of CKD. In cases of CKD, the failing kidneys lose the capacity to concentrate the urine maximally, which means that they must excrete more water to eliminate the solutes acquired in the diet. As a consequence, patients are forced by thirst to drink more water to cover the loss linked to solute excretion [13].

About $15.3 \%$ of the participants think that polyuria is one of the symptoms of CKD. Nocturnal polyuria has been well known in renal insufficiency [14]. As renal function deteriorated in CKD, natriuresis was enhanced during the night with nocturnal blood pressure elevation. This increase in nocturnal urine volume seemed related to osmotic diuresis mainly by natriuresis rather than to water diuresis or urea excretion [15].

About $68.6 \%$ of the participants were found to think that anuria is one of the symptoms of CKD. However, anuria usually associated with acute kidney injury [16] [17] rather than CKD, which might be associated with oliguria in some of the advance stages of the disease [18]. About $73.6 \%$ of the participants were found to think that urine smell change is one of the symptoms of CKD. Although this feature was uncommon [19], but it was stated by the majority of the participant in the present study. About $74.7 \%$ of the participants were found to assume that difficulty in urination is one of the symptoms of CKD. Though, we didn't come across study supporting this assumption, but we aimed at exploring the perception of the population towards some factors, which may regress the early detection of CKD.

About $83.6 \%$ of the participants were found to believe that side pain is one of the symptoms of CKD. There are several studies that evaluate the deleterious impact of pain in patients with CKD. The prevalence of pain has been estimated at approximately $50 \%-70 \%$ in patients with advanced CKD. The causes of pain in CKD patients are often unrelated to the renal disease and can be categorized as neuropathic (pain due to nerve damage) or nociceptive (pain due to tissue damage) in nature [20].

Regarding regular renal function testing, the majority of participants were found to ignore that, even if they are at risk of developing CKD. Most of those who were diagnosed with CKD were detected by chance. Continuous increase in the number of patients with ESRD demand early detection of CKD. CKD in ear- 
ly stages occurs frequently in the studied population. The proposed diagnostic algorithm seems to be a powerful tool to identify subjects at risk of CKD. The role of nocturia as an independent predictor of albuminuria, both in the general population and in people without diabetes or hypertension, should be further examined [21].

The limitations of the present study include its cross-sectional settings and predominance of females compared to males.

\section{Conclusion}

The awareness towards CKD manifestation is relatively low, which necessitates the important of community based intervention including health educational programs. Implementing of continuous screening programs at community based can reduce the burden of CKD, as well as, increasing the level of awareness.

\section{Acknowledgements}

Authors would like to thank Tamam Zamil Mutni Alshammari and Osama Saud H. Aljameel, for their assistance in data acquisition.

\section{Conflicts of Interest}

The authors declare no conflicts of interest regarding the publication of this paper.

\section{References}

[1] Jha, V., Wang, A.Y. and Wang, H. (2012) The Impact of CKD Identification in Large Countries: The Burden of Illness. Nephrology Dialysis Transplantation, 27, iii32-8. https://doi.org/10.1093/ndt/gfs113

[2] Almualm, Y. and Huri, H.Z. (2015) Chronic Kidney Disease Screening Methods and Its Implication for Malaysia: An in Depth Review. Global Journal of Health Science, 7, 96-109. https://doi.org/10.5539/gjhs.v7n4p96

[3] Jha, V., Garcia-Garcia, G., Iseki, K., et al. (2013) Chronic Kidney Disease: Global Dimension and Perspectives. Lancet, 382, 260-272.

https://doi.org/10.1016/S0140-6736(13)60687-X

[4] Kim, C.S. and Kim, S.W. (2014) Vitamin D and Chronic Kidney Disease. The Korean Journal of Internal Medicine, 29, 416-427. https://doi.org/10.3904/kjim.2014.29.4.416

[5] Duranton, F., Brunet, P., Laville, M., et al. (2014) Preventing Chronic Kidney Disease in France: Advantages, Feasibility and Concerns. Néphrologie \& Thérapeutique, 10, 492-499. https://doi.org/10.1016/j.nephro.2014.06.007

[6] National Kidney Foundation (2002) K/DOQI Clinical Practice Guidelines For Chronic Kidney Disease: Evaluation, Classification, and Stratification. American Journal of Kidney Diseases, 39, S1-266.

[7] Al-Sayyari, A.A. and Shaheen, F.A. (2011) End Stage Chronic Kidney Disease in Saudi Arabia. A Rapidly Changing Scene. Saudi Medical Journal, 32, 339-346.

[8] Ahmed, H.G., Ginawi, I.A., Alshammari, F.D., Elasbali, A.M., Eltom, F.M. and Al-Hazimi, A.M. (2014) Current Burden of Diabetes in Kingdom of Saudi Arabia in 
an Epidemiological Survey. Egyptian Academic Journal of Biological Sciences, 6, 85-91.

[9] Ahmed, H.G., Ginawi, I.A. and Al-Hazimi, A.M. (2014) Prevalence of Hypertension in Hail Region, KSA: In a Comprehensive Survey. International Journal of Sciences: Basic and Applied Research, 17, 288-296.

[10] Ahmed, H.G., Ginawi, I.A., Elasbali, A.M., Ashankyty, I.M. and Al-Hazmi, A.M. (2014) Prevalence of Obesity in Hail Region, KSA: in a Comprehensive Survey. Journal of Obesity, 2014, Article ID: 961861, 5 p.

[11] Brown, M.A., Collett, G.K., Josland, E.A., Foote, C., Li, Q. and Brennan, F.P. (2015) CKD in Elderly Patients Managed without Dialysis: Survival, Symptoms, and Quality of Life. Clinical Journal of the American Society of Nephrology: CJASN, 10, 260-268. https://doi.org/10.2215/CJN.03330414

[12] Judd, E. and Calhoun, D.A. (2015) Management of Hypertension in CKD: Beyond the Guidelines. Advances in Chronic Kidney Disease, 22, 116-122. https://doi.org/10.1053/j.ackd.2014.12.001

[13] Choi, H.Y., Park, H.C. and Ha, S.K. (2015) High Water Intake and Progression of Chronic Kidney Diseases. Electrolytes \& Blood Pressure: E \& BP, 13, 46-51. https://doi.org/10.5049/EBP.2015.13.2.46

[14] Natochin, Iu.V. and Bogolepova, A.E. (2000) Possible Mechanisms of Polyuria in Progressive Chronic Renal Failure. Terapevticheskii Arkhiv, 72, 15-20.

[15] Fukuda, M., Motokawa, M., Miyagi, S., et al. (2006) Polynocturia in chronic Kidney Disease Is Related to Natriuresis Rather than to Water Diuresis. Nephrology Dialysis Transplantation, 21, 2172-2177. https://doi.org/10.1093/ndt/gfl165

[16] Choi, H.M., Kim, S.C., Kim, M.-G., Jo, S.-K., Cho, W.Y. and Kim, H.K. (2015) Etiology and Outcomes of Anuria in Acute Kidney Injury: A Single Center Study. Kidney Research and Clinical Practice, 34, 13-19. https://doi.org/10.1016/j.krcp.2014.11.002

[17] Jung, H.-Y., Lee, J.H., Park, Y.-J., et al. (2016) Duration of Anuria Predicts Recovery of Renal Function after Acute Kidney Injury Requiring Continuous Renal Replacement Therapy. The Korean Journal of Internal Medicine, 31, 930-937. https://doi.org/10.3904/kjim.2014.290

[18] Oakes, R.S., Kirkham, J.K., Nelson, R.D. and Siegler, R.L. (2008) Duration of Oliguria and Anuria as Predictors of Chronic Renal-Related Sequelae in Post-Diarrheal Hemolytic Uremic Syndrome. Pediatric Nephrology, 23, 1303-1308. https://doi.org/10.1007/s00467-008-0799-9

[19] Kuravatti, S., David, M.P. and Indira, A.P. (2016) Oral Manifestations of Chronic Kidney Disease-An Overview. International Journal of Contemporary Medical Research, 3, 1149-1152.

[20] Scott, D. (2015) Cohen and Sara Davison. Chronic Renal Disease, Chapter 71, Pain and Chronic Kidney Disease. 854-860.

[21] Król, E., Rutkowski, B., Czarniak, P., et al. (2009) Early Detection of Chronic Kidney Disease: Results of the PolNef Study. American Journal of Nephrology, 29, 264-273. 